\title{
How Rule Consequentialism Avoids Boonin's Implausible Conclusion
}

\author{
TIM MULGAN \\ University of Auckland and University of St Andrews
}

\begin{abstract}
David Boonin's Implausible Conclusion says a person (Wilma) who deliberately chooses to conceive a blind child when she could, at no significant cost to herself, have conceived a sighted child instead does nothing morally wrong. Boonin argues that we should accept his Implausible Conclusion, in part because every moral theory that avoids that conclusion has other implications that are even less palatable. I argue that Rule Consequentialism can avoid Boonin's Implausible Conclusion without leading to greater absurdities. My focus is Boonin's fifth premise in the non-identity argument, or the claim that "if an act does not wrong anyone, then the act is not wrong." I introduce an imaginary case where an act that wrongs no one seems to be very wrong. This cases involves a future refusal to avoid imminent human extinction by costlessly launching a Generation Starship programme whereby humanity would continue in space. I argue that this refusal is intuitively wrong, even though it wrongs no one. Any acceptable moral theory must accommodate this intuition. This requirement makes Rule Consequentialism more impersonal and demanding, which enables Rule Consequentialism to condemn Wilma's choice, solve the non-identity Problem, and avoid Boonin's Implausible Conclusion.
\end{abstract}

Keywords: David Boonin, Non-Identity Problem, Rule Consequentialism, Human Extinction, Derek Parfit.

\section{INTRODUCTION}

In his excellent, thorough, and thought-provoking book The Non-Identity Problem and the Ethics of Future People, David Boonin argues that we 
should accept his Implausible Conclusion, in part because every moral theory that avoids that conclusion has other implications that are even less palatable. I argue that Rule Consequentialism can avoid Boonin's Implausible Conclusion without leading to greater absurdities. I cannot fully demonstrate such an ambitious claim in this short paper. My aim here is to sketch the resources available to Rule Consequentialism, highlight the challenges faced by its rivals, and motivate further exploration of Rule Consequentialist responses to Parfit's Non-Identity Problem (Parfit 1984: 351-379).

Boonin's Implausible Conclusion concerns the following case:

Wilma's Decision: Wilma deliberately chooses to conceive blind Pebbles when she could have, by taking a small pill once a day for two months, conceived sighted Rocks instead. Pebbles has a life worth living, but Rocks would have enjoyed a better life.

The Implausible Conclusion says that Wilma's act of conceiving Pebbles is not morally wrong. (Boonin 2014:5-all subsequent unattributed references are to this book). It is arrived at through the following line of reasoning:

P1: Wilma's act of conceiving now rather than taking a pill once a day for two months before conceiving does not make Pebbles worse off than she would otherwise have been.

P2: If A's act harms B, then A's act makes B worse off than B would otherwise have been.

P3: Wilma's act of conceiving now rather than taking a pill once a day for two months before conceiving does not harm anyone other than Pebbles.

P4: If an act does not harm anyone, then the act does not wrong anyone.

P5: If an act does not wrong anyone, then the act is not morally wrong.

C: Wilma's act of conceiving Pebbles is not morally wrong (27).

My focus is Boonin's fifth premise - the claim that if an act does not wrong anyone, then the act is not morally wrong. In his Chapter 6 , Boonin critiques various proposals to 'identify a property that can make an act wrong even if the act does not wrong anyone' (149). These include 'solutions based on appeals to utilitarian and consequentialist principles, in both act- and rule- forms, and to Parfit's Principle Q, as well as solutions based on considerations of group rights and of virtue.' (149) While Boonin claims that each of these proposals ultimately fails, I will argue in this paper that 
Rule Consequentialism has the resources to avoid the Implausible Conclusion and dissolve the non-identity problem.

\section{A NIHILISTIC CONCLUSION}

I focus on an imaginary case where an act that wrongs no one seems to be very wrong:

Generation Starship: In some future century, scientists discover that deadly cosmic rays will hit the Earth in two hundred years, instantly and painlessly killing all living things and rendering the Earth uninhabitable. We cannot prevent this. However, we can avoid total human extinction by constructing interstellar 'generation starships' where a small population and their descendants will continue the human story in space. ${ }^{1}$ Scientists also discover that ordinary humans could never survive in space. Only specially genetically engineered individuals can hope to survive the rigours of starship life. But these interstellar people could not survive on Earth. They can only flourish in space. Thanks to advances in technology since the twenty-first century, we know both that the interstellar people would enjoy very rich lives and that the cost to present people of launching the generation starship programme is comparatively low. Suppose we collectively decide not to launch the generation starship programme. (Perhaps Boonin's book has persuaded us that this would not be wrong.) When the cosmic rays strike, humanity goes extinct. Consciousness disappears from the cosmos, never to return.

This tale is very unrealistic. I explore the ethics of plausible generation starship cases more fully elsewhere (Mulgan forthcoming a, forthcoming b). Complicating factors include: (a) the construction of a successful generation starship programme using any currently imaginable technology would be very costly, very uncertain, and involve very high risks of very bad outcomes both for future interstellar people and for their descendants on some hostile planet; (b) generation starships would pose an existential threat to any indigenous life on other planets; (c) launching generation starships thus risks imposing on future colonists a morally unbearable choice been xenocide and survival; and (d) we could never be certain that cosmic rays were coming, that they couldn't be stopped, that our extinction wouldn't pave the way for either the evolution of superior terrestrial rational beings or the successful colonization of an empty Earth by

1 This scenario is familiar in speculative fiction - classic examples include Aldiss (1958) and Heinlein (1963). For scholarly discussion, see Caroti (2011). 
superior extra-terrestrials, and so on.

In this paper, I set all these complications aside. I seek an intuitively clear case, not a feasible one. My tale's artificial features are designed to rule out two familiar moves in the non-identity literature. First, realistic extinction threats invariably involve clear harms to present people or to future people who would have existed whatever we do, such as people killed by meteor strikes, catastrophic climate change, pandemic, alien invasion, runaway AI or nanotechnology etc. By contrast, my tale involves pure mere addition: if we launch generation starships, then we produce a future whose inhabitants would never otherwise have existed at all. Second, I also stipulate that we know that if we create generation starships, then the future quality of life will be positive. This is a very controversial assumption, but I retain it here because (a) it is a common presupposition in current philosophical debates about extinction (e.g., Beckstead 2013, Kaczmarek 2017); and (b) if we question this assumption, then it is far from obvious that it would be wrong to embrace human extinction.

For this paper, I make two assumptions about my Generation Starship tale:

1. No one is wronged by this decision.

2. When we decide not to launch the generation starship programme and thereby bring the human story to an abrupt end, we behave very wrongly.

Both claims are controversial. But both are also plausible. A full defense of my first assumption - that no one is wronged - is beyond the scope of this paper. But such a defense could easily draw on Boonin's own arguments in earlier chapters. If we don't launch generation starships, then the interstellar people never exist. So they have not been wronged. And no one else is wronged either. ${ }^{2}$

My second assumption is that our behavior is wrong. Many people will insist that we behave very wrongly because it is always very wrong to fail to prevent imminent human extinction at comparatively little cost to oneself. Perhaps failing to avoid extinction is less wrong than deliberately causing

2 What about children born in the last generation before the cosmic rays hit? Their lives are cut tragically short. Don't we wrong them? We could retell the story to remove this anomaly. (If we stop reproducing 50 years before the cosmic rays hit and use robots to meet the needs of the last humans, then no life is tragically short.) Alternatively, we could agree with Boonin himself that these people are not wronged, because (for reasons familiar from Parfit's Depletion vs Conservation and Risky Policy tales - Parfit 1984: 361-4, 371-2) they wouldn't otherwise have existed at all (Boonin 2014: chapter five). 
it. But it is still very bad. This reaction is unsurprisingly (more or less) universal among consequentialists. But it is also very common among non-consequentialists, including many theorists who do not think it is generally wrong to fail to produce good outcomes in non-identity cases. Consider three representative quotations:

"Most of us believe that human extinction would be the worst of those possible tragedies that have more than a negligible probability of actually occurring" (McMahan 2013: 26).

"The Earth may remain inhabitable for at least a billion years. ... Our descendants might, I believe, make the further future very good. But that good future may also depend in part on us. If our selfish recklessness ends human history, we would be acting very wrongly. Such acts might be worse for no one; but, as I have argued, that fact could not justify these acts" (Parfit 2011: vol 2, 616).

"Surely, if we developed a pill enabling each of us to live wonderful lives for 120 years it would be terrible for us to take the pill if the cost of doing so were the extinction of humanity" (Temkin 2012: 414 ${ }^{3}$ ).

By analogy with Boonin's Implausible Conclusion, I will say that these philosophers all reject:

The Nihilistic Conclusion: When we decide not to launch the generation starship programme and thereby bring the human story to an abrupt end, we do not do anything that is morally wrong.

The intuition that it is wrong to fail to avoid human extinction at comparatively little cost is, in some ways, an extreme example of the standard non-identity intuition that is Boonin's main target in his book. Boonin could therefore simply bite the bullet and insist that, counterintuitive as it may seem, it is not wrong to fail to launch Starships and thereby bring about the premature end of the human story. If so, my new example would serve to highlight the counter-intuitiveness of his position.

I am not sure how Boonin himself will respond to this particular case. However, I am confident that many people who are fully persuaded by Boonin's defense of the Implausible Conclusion would still baulk at accepting my Nihilistic Conclusion. There does seem to be something special about extinction-avoidance. My question in this paper is whether Boonin could accommodate this asymmetric response. Can he distinguish my Starship case from his original Wilma case?

3 Temkin adds in a footnote that this claim 'is almost as obvious as any claim can be in the normative domain' (Temkin 2012: 414). 
If my goal were simply to undermine Boonin's Premise Five, then a single case of wrongness where no one is wronged would suffice. I would then be simply begging the question against Boonin by assuming that my Starship provides such a case. But my goal here is more ambitious. I will argue that Boonin cannot treat extinction as a special case. If we reject my Nihilistic Conclusion, we are driven to reject his Implausible Conclusion as well.

Suppose we accept that our action in Starship is wrong. We must then explain why (and when) acts can be wrong even if they wrong no one. Boonin argues that those who reject his Implausible Conclusion must provide a moral theory ( $\mathrm{T}$ ) that avoids that conclusion also meets the following three constraints:

1. Independence: $\mathrm{T}$ must be justified independently of the fact that it avoids the Implausible Conclusion. (We can't introduce an ad hoc principle simply because it implies that Wilma's act is wrong.) (20)

2. Robustness: $\mathrm{T}$ must be strong enough to warrant rejecting any weakened versions of Boonin's premises that are still strong enough to generate the Implausible Conclusion. (22)

3. Modesty requirement: $\mathrm{T}$ must not be so robust that it generates implications even more implausible than the Implausible Conclusion. (22)

Analogously, if we are to reject the Nihilistic Conclusion, then we need a moral theory $\mathrm{T}^{*}$ that avoids that conclusion while satisfying Boonin's three constraints with respect to the Nihilistic Conclusion. For instance, just as Boonin rejects ad hoc solutions tailored to avoid the Implausible Conclusion, we must also reject ad hoc solutions to the Nihilistic Conclusion. I will argue that the best candidate for $\mathrm{T}^{*}$ is a version of Rule Consequentialism (hereafter RC) that also avoids the Implausible Conclusion. Therefore, rejecting the Nihilistic Conclusion leads us to reject the Implausible Conclusion.

\section{THERE IS NO ALTERATIVE}

The most obvious challenge for my argument is robustness. Generation Starship and Wilma's Decision are very different kinds of cases. Surely many possible moral principles will judge the former to be morally (very) wrong without finding any fault with the latter? After all, Wilma herself might heartily agree that it is always wrong to fail to avoid human extinction 
at comparatively little cost.

My ambitious reply is that any theory that can avoid the Nihilistic Conclusion while meeting Boonin's independence and modesty constraints will also avoid the Implausible Conclusion. It is easy to construct rival theories that seem to avoid the Nihilistic Conclusion without having any implications for Wilma's case. But such rivals either (a) lack an independent rationale or (b) have other even more implausible implications.

The challenge for alternatives to RC is to say why our behavior is wrong without merely redescribing it. Merely asserting that it is wrong to fail to avoid imminent human extinction at little cost' doesn't explain anything.

An adequate refutation of all alternatives to $\mathrm{RC}$ is far beyond the scope of this paper. In this section, my aim is only to illustrate the challenges facing such alternatives, by using two representative rivals. The philosophical literature on human extinction offers three main explanations for the badness of human extinction:

1. Utilitarian: Human extinction would be bad because it does not maximize future human well-being (e.g., Beckstead 2013, Kaczmarek 2017).

2. Individual Meaning: Human extinction would be bad because, if there were no future people, our present projects would be drained of meaning (e.g., Scheffler 2013, 2018).

3. Sui Generis: Human extinction has a special sui generis badness over-and-above any impact on either the lives of individuals or total future well-being (e.g., Frick 2017, Temkin 2015).

RC exemplifies the first type of explanation. One prominent example of the second type is Samuel Scheffler's argument that, if you knew that the world would end thirty days after your death, then this would drain your life projects of much of their current meaning (Scheffler 2013, 2018). Scheffler's approach may seem ideal for Boonin's purposes. Extinction is bad because, despite initial appearances to the contrary, it is bad for individuals. We therefore have no counter-example to Boonin's argument. Unfortunately, Scheffler-style meaning is not sufficient to help Boonin. Even if imminent extinction has some negative impact on present individuals, that impact does not seem sufficient to explain all the badness of extinction. Most importantly, while considerations of meaning might explain why we wouldn't allow the human species to become extinct, it does nothing to explain why this would be wrong. For instance, in an earlier contribution to the debate, Brooke Trisel argues that some valuable projects are 
sufficiently self-contained to be immune to extinction-driven meaningloss (Trisel 2004). Suppose we agree with Trisel. Therefore, instead of launching generation starships, we decide to simply exchange our futureoriented projects for self-contained ones (perhaps we inaugurate a new religion of purely self-contained contemplation of the cosmos). We might be making a prudential error - especially if Trisel turns out to be mistaken. But prudential errors of this sort are not normally regarded as moral errors.

My representative example of a sui generis explanation of the badness of extinction is suggested by Temkin (2015):

Temporal Consequentialism (TC): An outcome's value depends, not only on the quality of individual lives, but also on how those lives are distributed through time. It is not always better if there are more happy people. But it is always better if there are more times when happy humans live. Adding extra happy people at already inhabited times does not improve things, but adding them at otherwise empty times does. And failing to add such lives is prima facie wrong.

Unlike most non-consequentialist theories, TC rejects Boonin's P5. Failing to costlessly prevent imminent human extinction is wrong even if no one is wronged. Unlike standard utilitarian consequentialism, however, TC denies that failing to maximize aggregate happiness at a particular time is wrong. TC thus delivers the two verdicts we are seeking: it condemns our decision not to launch generation starships, but it says nothing against Wilma.

TC seems to fit the bill. Unfortunately, it has two failings. TC lacks an independent case and it is immodest. These failings are linked, because the principal argument for TC is presumably that it captures our considered moral judgements (Temkin 2012, 2015). Consider the following choice:

Leave or Remain: Humanity faces an existential threat. We have only two options. We can either (a) maximize the quality of life on Earth for a short time, or (b) pour all our resources into a very Spartan shortlived generation starship programme. If we Remain, then 100 million people will enjoy good lives for one century, and then humanity becomes extinct. If we Leave, then during each of a thousand centuries, 100,000 people will enjoy less good lives, and then humanity becomes extinct. Temporally neutral consequentialists prefer Remain to Leave. The numbers are identical, and everyone is happier. Suppose also that this is a Same People Choice where both outcomes contain the same individuals (Parfit 1984: 356). (Perhaps Leave involves cryogenic 
storage in outer space, with 100,000 people thawed each century.) If we Leave, then every individual is worse-off than she would otherwise have been. Temporally-neutral non-consequentialists will thus also prefer Remain. By contrast, TC insists that Leave has one very significant advantage: Humanity lives for an extra 999 centuries! If the difference in individual quality of life between Remain and Leave is sufficiently small, then Leave must be superior all-things-considered.

TC's verdict is hard to believe. Suppose we choose Leave. We make 100 million people worse-off than they would otherwise have been. Could we then justify ourselves to those people simply by noting that their sacrifice ensures that humanity survives longer? I doubt they would be very impressed! ${ }^{4}$

Of course, I have not refuted all alternatives to RC. But I have hopefully done enough to show that constructing an independent moderate robust theory $\mathrm{T}^{*}$ is not straightforward. We cannot assume that the Implausible and Nihilistic Conclusions can be so easily separated.

\section{RULE CONSEQUENTIALISM}

For any consequentialist, our decision in Generation Starship is very

4 To further highlight TC's implausibility, consider a first-person analogue:

Duplication: You are about to be duplicated ten times. Each copy will live on a different planet. There will be no interaction between them. Does it matter to you whether those copies exist simultaneously or consecutively? Presumably not.

You might reply that you would rather not be duplicated at all. Your original self could then live on ten successive planets. This is because what matters to you is not how long you exist, but how your life's narrative goes. But, as the following tale reveals, this consideration counts against TC.

Time Travel: Each year, you have two options. You can step into either (a) a device that only transports you to another planet, or (b) a device that both transports you to another planet and sends you one year into the past. Either way, you will live in different places. If you merely teleport, then you also live through many different time periods. If you instead time travel, then you always live through the same time period. Both devices are perfectly reliable. But mere teleportation carries a significant cost. Life is getting progressively worse everywhere. If you merely teleport, your quality of life continually declines. If you timetravel, it remains constantly high.

I suggest that there is no self-interested reason to opt for mere teleportation. If timetravel offers a richer life, then it is irrational to refuse it. What matters to you is the internal narrative duration of your life, not its occupation of external time periods. Similarly, temporally-neutral consequentialists will insist that what matters morally in Leave or Remain is the internal perspective of the 100 million inhabitants, not how they happen to be spread through time. 
wrong. The loss of all that future happiness is a moral catastrophe. Any plausible form of RC must avoid the Nihilistic Conclusion. The two crucial questions are:

1. How does RC deliver this result?

2. What (if anything) does this tell us about RC's response to Wilma's choice?

I will argue that RC's best response to extinction threats enables it to avoid the Implausible Conclusion. In this section, I present a very abbreviated independent case for RC. The main justification for this brevity is that Boonin himself does not question the independence of RC (175-8).

RC offers a moderate, liberal alternative to act utilitarianism. RC pictures morality as a collective enterprise, and evaluates moral codes by their collective impact on human well-being. RC's fundamental moral questions are: 'What if we did that?', and 'How should we live?' (Hooker 2000, Mulgan 2001: 53-103, 2006: 130-160, 2009, 2015, 2017.)

RC ranks competing moral codes by asking what would happen if everyone in the next generation internalized any given code. (This sets aside the cost of changing existing moral beliefs, but factors-in the difficulty of trying to internalize a very demanding ethic.) We then evaluate acts by asking what someone who had internalized the ideal code (call her 'the RC ideal agent') would feel free to do in that situation.

We cannot hope to specify the ideal code in any detail. At most, we can identify some of its general features. But often that is enough. We might, for instance, be confident that the ideal code does not support gratuitous torture, even if we don't know exactly what it says about other issues.

The independent case for RC has the following elements:

1. RC captures a perennially attractive picture of morality as a collective human enterprise passed on from one generation to the next.

2. RC follows the spirit of the classical utilitarians, especially Jeremy Bentham and J. S. Mill, who also began with simple moral principles and allowed complexity to emerge empirically in response to our evolving knowledge of human nature and the human situation.

3. Hooker argues that 'the best argument for rule consequentialism is that it does a better job than its rivals of matching and tying together our moral convictions' (Hooker 2000: 101). The ideal code must be internalized by a new generation of human beings. Human 
nature is not infinitely plastic. Any plausible ideal code will include familiar moral dispositions such as honesty, generosity, promisekeeping, courage, murder-aversion, and so on. The RC ideal agent will not walk callously past children drowning in ponds, take pleasure in the sufferings of others, or reject the basic goods of human life.

4. However, RC does not merely recapitulate common-sense morality. It also improves it. Our actual moral practice is not optimal from an RC perspective, especially when it comes to its impact on the well-being of distant future people. RC will depart from commonsense morality by including a stronger reason to promote the good, a stronger prima facie obligation to confer benefits on others (and avoid harming them) when one can do so at comparatively little cost to oneself, a greater willingness to extend these obligations to cover future people even in Different People Choices, a greater general commitment to temporal impartiality, and so on (Mulgan 2006, 2015, 2017).

I conclude that invoking RC to avoid the Nihilistic and Implausible Conclusions is not ad hoc. And it is easy to see how RC must avoid the former. The moral code that maximises future well-being won't allow us to gratuitously fail to avoid imminent human extinction. The real question is whether or not RC also avoids the Implausible Conclusion.

\section{HOW RULE CONSEQUENTIALISM AVOIDS THE IMPLAUSIBLE CONCLUSION}

What does RC say about Wilma? Two RC commitments push in opposite directions here. On the one hand, RC is consequentialist. We choose an ideal code that best promotes future human well-being. The RC ideal agent surely accepts a more demanding and impersonal morality than we do. These features all suggest she will not condone Wilma's choice.

On the other hand, RC presents itself as a moderate liberal alternative to act consequentialism (Hooker 2000). An ideal code that is too demanding or impersonal could not be taught to human beings. Proponents of RC argue (i) that $\mathrm{RC}$ recognizes a broad sphere of personal moral freedom where agents are free to not maximally promote the good, (ii) that reproductive freedom is a central moral commitment that RC must respect, and (iii) that, despiteits generalcommitment toimpersonaldemandingness, 
the ideal code may also include person-affecting principles, priority to actual people over future people, and a rejection of procreative coercion. The RC ideal agent will not feel obliged to create the happiest children she possibly could. (Mulgan 2006: 172-3) This suggests she will not regard Wilma's choice as wrong. If sub-optimal procreation is permitted, then why shouldn't Wilma create Pebbles rather than Rocks?

As Boonin notes, earlier RC discussions of this very issue (including my own) leave open RC's final verdict on cases like Wilma's (178, citing Mulgan 2009: 131). However, I will now argue that, once it is updated to accommodate the full range of possible futures - including futures like my Generation Starship tale where extinction is at stake - RC will reject Wilma's choice. (The rest of this section abbreviates much longer discussions in Mulgan 2011, 2015, 2017.)

Wilma might reply that factoring these new futures into RC cannot affect her choice, for two obvious reasons. First, human extinction is not at stake in her decision. Second, even if human extinction were a relevant consideration, creating Pebbles seems no better or worse from the perspective of extinction-avoidance than creating Rocks. What could Wilma's decision to have a less-than-optimally-happy child possibly have to do with human extinction?

The answer is that, to reliably avoid imminent human extinction across the full range of possible futures, RC must abandon its commitment to a liberal ideal code that incorporates a permissive procreative ethic and a presumption of reproductive freedom. While such a code probably will be optimal in more favourable futures, it could lead to premature extinction if things go badly wrong. For instance, there are many possible futures where human life is very harsh and the survival of humanity demands (i) that very scarce resources must be carefully preserved for subsequent generations, (ii) that population size must be strictly monitored, and (iii) that people continue to reproduce even though they know both that their children's lives will be very grim and that bearing and raising children will reduce the quality of their own lives. One example would be a less rosy (but more realistic) generation starship scenario, where people endure very restricted and unpleasant conditions on starships in the hope that later generations will enjoy a much better life on a new planet. Future people committed to current ideas of reproductive freedom might reject such brutal starship lives out of hand, even if they were humanity's last best hope. This is not an acceptable result for RC. In futures where the survival of humanity depends on people having children even though they don't want to, the ideal moral agent must feel obliged to reproduce. 
Of course, Wilma does reproduce. She chooses to create Pebbles rather than either creating Rocks or having no child at all. Wilma might insist that a moral code that obliges people to have children who are much worse-off than Pebbles can hardly object to her decision. My reply is that, once it factors in the possibility of restricted futures and extinction risks, RC must make broader changes to its ideal code. RC will now select a much less permissive ideal code that rejects any presumption of reproductive freedom and also includes a much stronger obligation to do whatever one can to enhance future well-being. When making a procreative choice, the RC ideal agent will not feel free to consult her own desires when this would lead to a sub-optimal result in terms of future well-being. She would not feel free to indulge her own preferences in Wilma's situation, and therefore she will regard Wilma's sub-optimal creation of Pebbles as wrong.

We can easily imagine more flexible moral codes with fine-grained rules that would specify the optimal pattern of behavior in any particular future situation. ${ }^{5}$ These flexible codes would be designed to limit procreative freedom only in bleak futures, thereby avoiding extinction without compromising Wilma's decision. The crucial question is whether such logically possible codes would produce optimal results when internalized in a whole future generation. There are three general reasons to believe that the optimal RC code will not take this form. First, every increase in complexity makes it harder for a whole generation to successfully internalize a given code, thereby reducing its effectiveness. Second, extinction threats will take a great variety of forms, and a code whose stricter rules only come into play in 'extinction scenarios' might misfire very badly if agents were caught unawares. Third, the additional benefit of also safeguarding Wilma's freedom would not be sufficient to justify these costs - especially if, as I argue in the next section, an RC ideal code that condemns Wilma's choice can consistently sanction limited procreative freedom in other cases.

This is a very quick sketch of how RC might avoid the Implausible Conclusion. The argument rests on speculative empirical claims which are hard to verify. This is a general feature of arguments within RC, which RC's opponents often find unsatisfactory. My goal here is not to vindicate RC, but merely to demonstrate that, if RC can establish its general credentials as a plausible moderate alternative to Act Consequentialism that makes sense across a wide range of possible futures, then it can also reasonably hope to avoid the Implausible Conclusion.

5 I am grateful to an anonymous reviewer for pressing me on this point. 


\section{IS RULE CONSEQUENTIALISM IMMODEST?}

RC responds to restricted futures and extinction risks with a more demanding and impersonal ideal code. This ideal code provides RC's standard of right and wrong. RC concludes that Wilma's choice is wrong, thus avoiding Boonin's Implausible Conclusion. But is the price too high? Does RC's new demanding ideal code have other implications that are even worse than the Implausible Conclusion? ${ }^{6}$

Boonin contrasts Wilma's choice with two others:

1. Wilma*'s Choice: Wilma* has a medical condition which means she can only have blind children. Wilma* decides to have a child, who enjoys a very good life despite being born blind. (112-3, 121-2. 'Wilma*' is my label. Boonin himself presents this as an alternative version of Wilma's Choice)

2. Jane's Choice: Jane already has two children. She knows that her third child would be as happy as Rocks and that her other children would be no worse-off. Yet Jane decides not to have a third child. (171-2)

Boonin argues plausibly (i) that we intuitively think that, while Wilma's choice is wrong, neither Wilma* nor Jane does anything wrong, and (ii) that these intuitions are at least as compelling as our rejection of the Implausible Conclusion. Our moral theory T must avoid the Implausible Conclusion without implying that either Wilma* or Jane does anything wrong.

Boonin then confronts RC with a dilemma: 'The problem ... is that if autonomy is not valuable enough to grant Wilma the freedom to conceive Pebbles rather than Rocks, then it is not valuable enough to grant Jane the freedom to refrain from conceiving a third child in the case where she has a slight preference not to have another child.' (176)

RC values autonomy. Either that value is sufficient to permit Wilma's creation of Pebbles, or it is not. If it is, then RC cannot reject Boonin's Fifth Premise. If not, then RC cannot permit Jane not to have a third child. Boonin regards the latter as more absurd than the Implausible Conclusion.

6 RC is very controversial for reasons unrelated to future people, non-identity, or human extinction. The literature provides many general objections to RC. Boonin could borrow these objections and argue that RC is already too immodest. A full consideration of this move would take us too far afield. If RC fails on other grounds, then its ability to dissolve the non-identity problem is moot. However, in his book Boonin focuses on whether RC's response to non-identity is itself immodest, and I follow his lead here. (I am grateful to an anonymous referee for pressing me on this point.) 
RC has two options: differentiate or bite the bullet. I shall now briefly argue that both are promising.

RC can differentiate between Wilma*, Jane, and Wilma. Two features of $\mathrm{RC}$ are salient here:

1. The ideal code must be internalized, not merely followed. RC does not simply ask what those its idealized agents will do. It asks instead about their reasons, motives, or character, and about why they act as they do.

2. Boonin asks whether Wilma's action is wrong, not whether it should be socially sanctioned or legally prohibited. For RC, this is a firstpersonal question: Would the RC ideal agent feel free to act as Wilma does? RC ideal agents might not feel free to do what Wilma does, even if they agree that her reproductive freedom should not be subject to any socially or legally enforced constraints.

Intuitively, Wilma's choice is wrong, not only because it is suboptimal, but also (indeed, primarily) because there is no good reason for it. RC captures this natural thought. Wilma violates a prima facie obligation to confer benefits and promote future well-being when she can do so at little cost to herself. The RC ideal agent would only feel free to behave like this if she had a strong reason to do so. But what is Wilma's reason? And would the $\mathrm{RC}$ ideal agent regard it as a good reason?

Boonin discusses a similar objection: namely, that Wilma's act is wrong because it reflects a bad character (184-8). Boonin replies that this begs the question against Wilma (187-8). Wilma's character is deficient only if her act is wrong. But what if Wilma is a philosopher whose reason for thinking her behavior is permissible is that it wrongs no one?

Boonin's target here is not RC. And RC's objection to Wilma is not circular in this way. RC defines good and bad motives or character in terms of the ideal code, which in turn is chosen because it best promotes future human well-being. The ideal code must protect the interests of distant future people in non-identity cases. So it must ensure that earlier future people don't generally regard actions as permissible simply because they wrong no one. The RC ideal agent would not feel free to do something just because she knew it would wrong no one. Wilma needs another reason. But what else can Wilma say for herself?

By contrast, the RC ideal agent will treat Wilma* very differently. Recall that our ideal code must work effectively in broken futures where our present quality of life is no longer available. I argue elsewhere that this is best achieved if the threshold for acceptable procreation is relativized to 
the agent's situation (Mulgan 2006, 2011, 2015). People living in a broken future will feel free to have children even though they cannot provide anything approaching Rocks's quality of life. Wilma*'s situation is broken at the individual level. She too can only offer her child a diminished life. The RC ideal agent might well feel free to procreate in Wilma*'s situation. Therefore, RC judges that Wilma*'s does nothing wrong. Wilma cannot offer a similar justification, because her situation is not broken. She could offer a future child a better life.

This reply differentiates Wilma from Wilma*. But Jane's situation is not broken. Like Wilma, Jane fails to create the happiest child she could. She also fails to maximize future well-being. How could the RC ideal agent approve Jane's choice and reject Wilma's?

One answer is that a verdict of wrongness is much more threatening to Jane's reproductive autonomy than to Wilma's. If we judge that Jane acts wrongly, then we must conclude that she is obliged to have a child she doesn't want. If we judge that Wilma acts wrongly, then we must conclude that she is obliged to have a different child at comparatively little cost. These two obligations are not equally burdensome. 'Because I don't want another child' is a deeper reason than 'Because I don't want this (sighted) child'. RC can explain this intuitive distinction. Only in extreme circumstances will the RC ideal agent feel obliged to have a child she doesn't want. As Jane's circumstances are not extreme, she does no wrong.

I conclude that RC can differentiate the three situations: Wilma, Wilma*, and Jane. Alternatively, RC could bite the bullet, and accept that Jane is not morally free to choose. If RC takes this route, it will say, not that Jane is obliged to have a third child, but rather that she is obliged not to! For any consequentialist, the striking feature about Jane's choice is that the resources Jane would (inevitably) devote to her extra child's welfare could almost certainly produce much greater benefits elsewhere. As she already has two children, Jane can hardly argue that she must procreate because she has a burning desire to experience life as a parent (Cf. Weinberg 2015). Unless human extinction is a present threat, the RC ideal agent might not feel free to have another child in Jane's case. (Of course, this might also mean that Wilma's real fault is that, instead of having Pebbles, she should have no child at all.)

Are these implications absurd? Is RC guilty of immodesty here? I am not sure. It seems much less absurd to claim that Jane is obliged not to have a third child because there is so much good to be done in the world than to claim that Jane is obliged to have a third child because that child would have a good life. The latter claim strikes many non-consequentialists as intrinsically absurd, while the former is (merely) extremely demanding. 
Many people, of course, do find such extreme demands absurd. But RC can reply that, once we take on board the very real prospect of broken and empty futures, we must acknowledge a more demanding morality across the board. Extreme demandingness is no longer conclusive proof of immodesty.

I conclude, contra Boonin, that once we recognize that it must avoid the Nihilistic Conclusion, RC does have the resources to avoid the Implausible Conclusion and dissolve the non-identity problem. ${ }^{7}$

\section{BIBLIOGRAPHY}

Aldiss, B., 1958: Non-Stop, London: Faber and Faber.

Beckstead, N., 2013: On the overwhelming importance of shaping the far future, Rutgers $\mathrm{PhD}$ thesis.

Boonin, D., 2014: The Non-Identity Problem and the Ethics of Future People, Oxford: Oxford University Press.

Caroti, S., 2011: The Generation Starship in Science Fiction: A critical history 1934-2001, Jefferson, North Carolina: McFarland and Co.

Frick, J., 2017: “On the survival of humanity”, Canadian Journal of Philosophy 47: 344367.

Heinlein, R., 1963: Orphans of the Sky, London: Gollancz.

Hooker, B., 2000: Ideal Code, Real World, Oxford: Oxford University Press.

Kaczmarek, P., 2017: "How much is rule-consequentialism really willing to give up to save the future of humanity?", Utilitas 29: 239-249.

McMahan, J., 2013: “Causing People to Exist and Saving People's Lives”, Journal of Ethics 17: 5-35.

Mulgan, T., 2001: The Demands of Consequentialism, Oxford: Oxford University Press.

-2006: Future People, Oxford: Oxford University Press.

-2009: "Rule Consequentialism and Non-Identity", in Harming Future Persons, ed. M. Roberts and D. Wasserman, 115-134, Dordrecht: Springer.

-2011: Ethics for a Broken World, Durham: Acumen.

-2015: "Utilitarianism for a Broken World", Utilitas 27: 92-114.

-2017: "How should utilitarians think about the future?", Canadian Journal of Philosophy 47: 290-312.

Mulgan, T, forthcoming a: "What exactly is wrong with human extinction?", in Proceedings of the International Society for Utilitarian Studies, ed. C. Schmidt-Petri and M. Schefczyk, Karlsruhe: KIT Scientific Publishing.

Mulgan, T, forthcoming b: Future Worlds: The moral significance of Generation Starships, draft manuscript.

Parfit, D., 1984: Reasons and Persons, Oxford: Oxford University Press.

-2011: On What Matters, Oxford: Oxford University Press.

Scheffler, S., 2013: Death and the Afterlife, Oxford: Oxford University Press.

-2018: Why Worry about Future Generations? Oxford: Oxford University Press.

7 I am very grateful to two anonymous referees for helpful and insightful comments on an earlier draft. 
Temkin, L. S., 2012: Rethinking the Good, Oxford: Oxford University Press.

-2015: "Rationality with respect to people, places, and times", Canadian Journal of Philosophy 45: 576-608.

Trisel, B. A., 2004: "Human extinction and the value of our efforts", The Philosophical Forum 35: 371-391.

Weinberg, R., 2015: The Risk of a Lifetime: How, When, and Why Procreation May Be Permissible, Oxford: Oxford University Press. 